\title{
Left atrial to left ventricular valved conduit for a calcified mitral annulus and ascending aorta
}

\author{
Francisco Javier López-Rodríguez, MD, PhD, ${ }^{a}$ María Elena Arnáiz-García, MD, PhD, ${ }^{\mathrm{a}}$ \\ Manuel Barreiro-Pérez, MD, PhD, ${ }^{b}$ and José María González-Santos, $\mathrm{MD}, \mathrm{PhD},{ }^{\mathrm{a}}$ Salamanca, Spain
}

\footnotetext{
From the ${ }^{\mathrm{a} C a r d i o v a s c u l a r}$ Surgery Department and ${ }^{\mathrm{b}}$ Cardiac Department, Complejo Asistencial Universitario de Salamanca, Salamanca, Spain.

Disclosures: Authors have nothing to disclose with regard to commercial support.

Received for publication July 20, 2018; revisions received Sept 5, 2018; accepted for publication Sept 18, 2018; available ahead of print Nov 3, 2018.

Address for reprints: Francisco Javier López-Rodríguez, MD, PhD, Cardiac Surgery Department, Complejo Asistencial Universitario de Salamanca, Paseo de San Vicente 58-182, 37007 Salamanca, Spain (E-mail: fjlopez@ saludcastillayleon.es).

J Thorac Cardiovasc Surg 2019;157:e143-5

$0022-5223 / \$ 36.00$

Copyright $(C) 2018$ by The American Association for Thoracic Surgery

https://doi.org/10.1016/j.jtcvs.2018.09.089
}

Video clip is available online.

Extensive calcification of the mitral valve annulus (MA) represents a challenge during mitral valve surgery, which carries high perioperative risk. ${ }^{1,2}$ Aggressive debridement of the MA provides proper healing of the prosthesis sewing ring and avoids periprosthetic regurgitation, but increases the risk of cardiac rupture and circumflex artery injury. Techniques without MA debridement (eg, placement of the prosthesis at the mitral leaflets or atrial wall) reduce the possibility of ventricular rupture, but do not lower the risks for paravalvular leaks and a smallersized prosthesis than desired. Several reports have highlighted the feasibility of transcatheter mitral valve replacement under direct visualization in this setting.

Mitral valve bypass (MVB) with a left atrium to left ventricular valve conduit has been previously described to correct congenital mitral stenosis ${ }^{3}$ and as an alternative to mitral valve replacement in the presence of a severely calcified MA. ${ }^{4,5}$

We report our experience with a 66-year-old man who underwent aortic valve replacement 5 years ago that required an extended aortic endarterectomy. The patient remained asymptomatic until 1 year ago. He presented to our department with a recent history of frequent hospitalizations for heart failure. Transthoracic echocardiography reveled severe mitral valve stenosis (mean gradient, $15 \mathrm{~mm} \mathrm{Hg}$ ) with extensive MA calcification, mild tricuspid regurgitation, and mild dysfunction of both ventricles. Normofunctioning of the aortic prosthesis was confirmed. Systolic and diastolic pulmonary pressures in the right

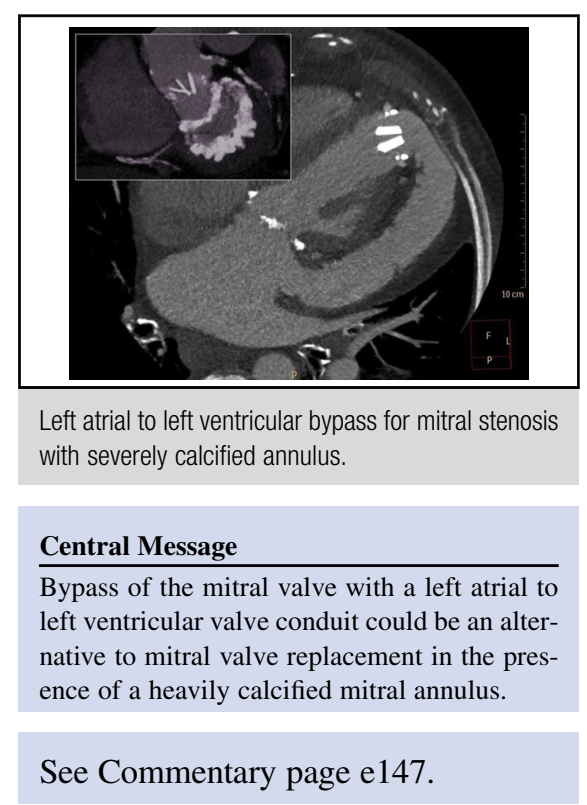

catheterization were $73 \mathrm{~mm} \mathrm{Hg}$ and $29 \mathrm{~mm} \mathrm{Hg}$, respectively. A computed tomography (CT) scan revealed intense calcification extending from MA to the left ventricle (Figure 1, A) and a porcelain aorta. Due to serious functional limitation, a surgical approach was considered. A heart transplant was ruled out due to high pulmonary hypertension. A transcatheter mitral valve approach was also discarded because CT scan simulation foresaw a high probability of paravalvular leak and left ventricular outflow tract obstruction. A plan for modified MVB was devised.

Surgery was performed through a repeat median sternotomy with arch and right atrial cannulation, without aortic crossclamp to avoid aortic calcification. Continuous carbon dioxide insufflation was used. An MVB was manufactured using an On-X Conform (CryoLife Inc, Kennesaw, Ga) mitral valve and a $30 \mathrm{~mm}$ graft. The graft was beveled and everted over the valve sewing ring (Figure 1, $B$ and $C$ ). They were attached with 4 interrupted 3-0 polypropylene stitches. After cardiopulmonary bypass was established, an apical left ventriculotomy was made and multiple interrupted pledgeted 3-0 polyester everted mattress sutures were placed around (Figure 1, D). The sutures were passed through the valve sewing ring and polyethylene terephthalate graft at the same time and tied down (Figure 2, $A$ and $B$ ). A 4-0 running polypropylene 


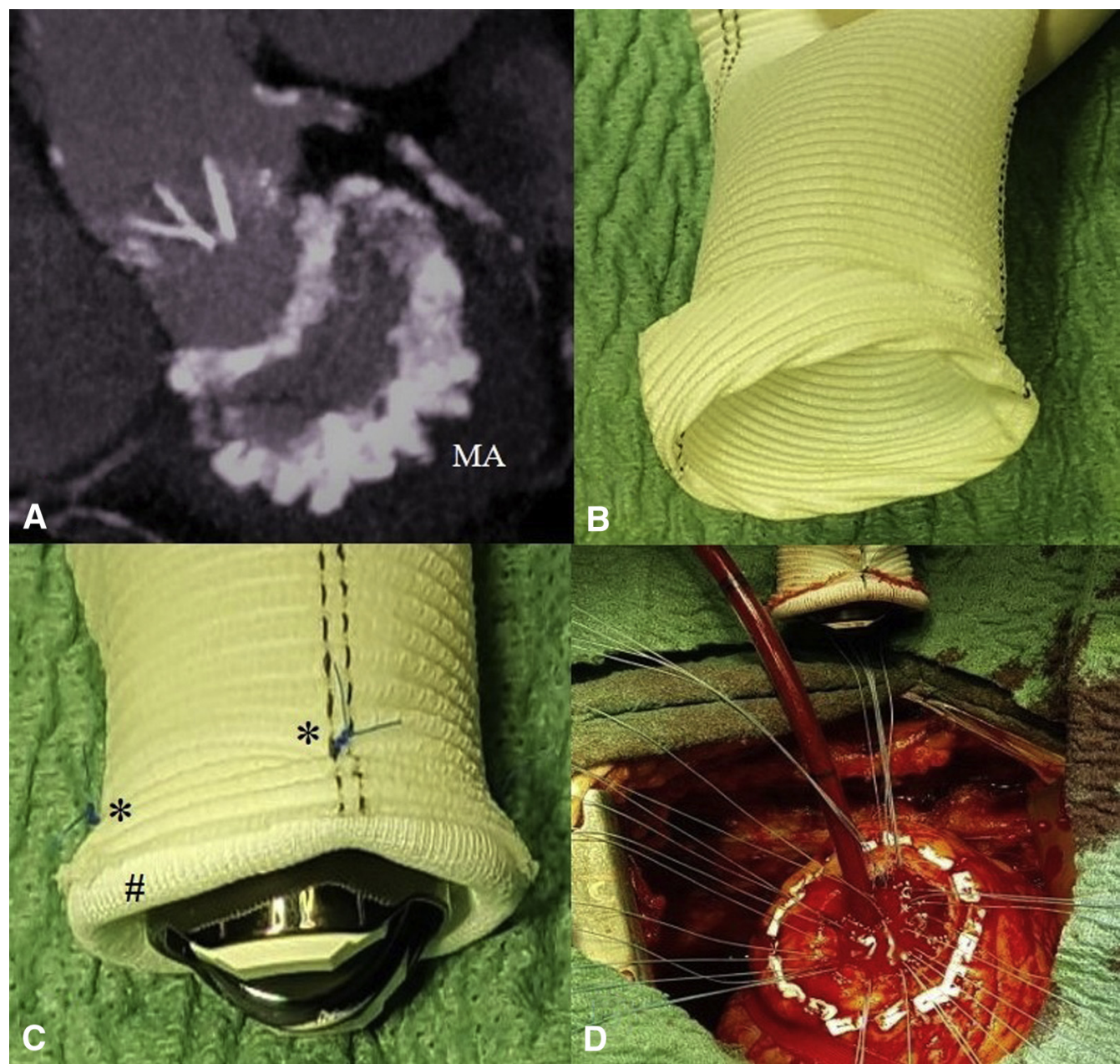

FIGURE 1. A, Preoperative computed tomography scan showing the intense calcification of the mitral annulus (MA). B, A 30-mm polyethylene terephthalate graft was beveled and everted. C, The graft was everted over the On-X Conform (CryoLife Inc, Kennesaw, Ga) mitral valve sewing ring (\#) and sewn with four interrupted 3-0 polypropylene stitches $(*)$. D, An apical left ventriculotomy was made and interrupted pledgeted 3-0 polyester everted mattress sutures were placed around.

suture and surgical adhesive were used to reinforce the anastomosis. The left atrium appendage was amputated (Figure 2,C) and sewn to a portion of the graft with a running 4-0 polypropylene suture (Figure 2,D). After de-airing the graft and heart using usual maneuvers, both portions of the graft were sewn together (Figure 2,E). Cardiopulmonary bypass was discontinued without difficulty after 100 minutes. Postoperative echocardiography revealed a mean gradient of $2 \mathrm{~mm} \mathrm{Hg}$ across MVB and a CT scan showed a wide patent conduit (Figure 2,F). The postoperative course was uneventful and he was discharged home on postoperative day 10. After 8 months, the patient is alive and in good condition.

We describe a modified technique (Video 1) of the MVB procedure outlined by Said and colleagues. ${ }^{4}$ We used a bigger size and a mitral prosthesis instead of an aortic valve conduit, which could result in lower gradients. Furthermore, the sewing ring of the valve was sewn directly to the ventriculotomy instead of to an intermediate length of the conduit to avoid any dead space between prosthesis and left ventricle. These modifications could reduce the risk of graft thrombosis. The pledgeted sutures around the ventriculotomy were used to sew the prosthesis and polyethylene terephthalate graft to the ventricle, like the sewing ring of a ventricular assist device. This anastomosis could simplify the technique and be more hemostatic. To avoid a possible interference of ventricular tissue in the movement of the leaflets, we used an On-X Conform prosthesis. Its cylindrical housing shelters almost the entire motion of the leaflets and could protect them from impingement by ventricular tissue (Figure 2, $A$ ).

We have described a simple and reproducible modified MVB technique. It could be an alternative to mitral valve 


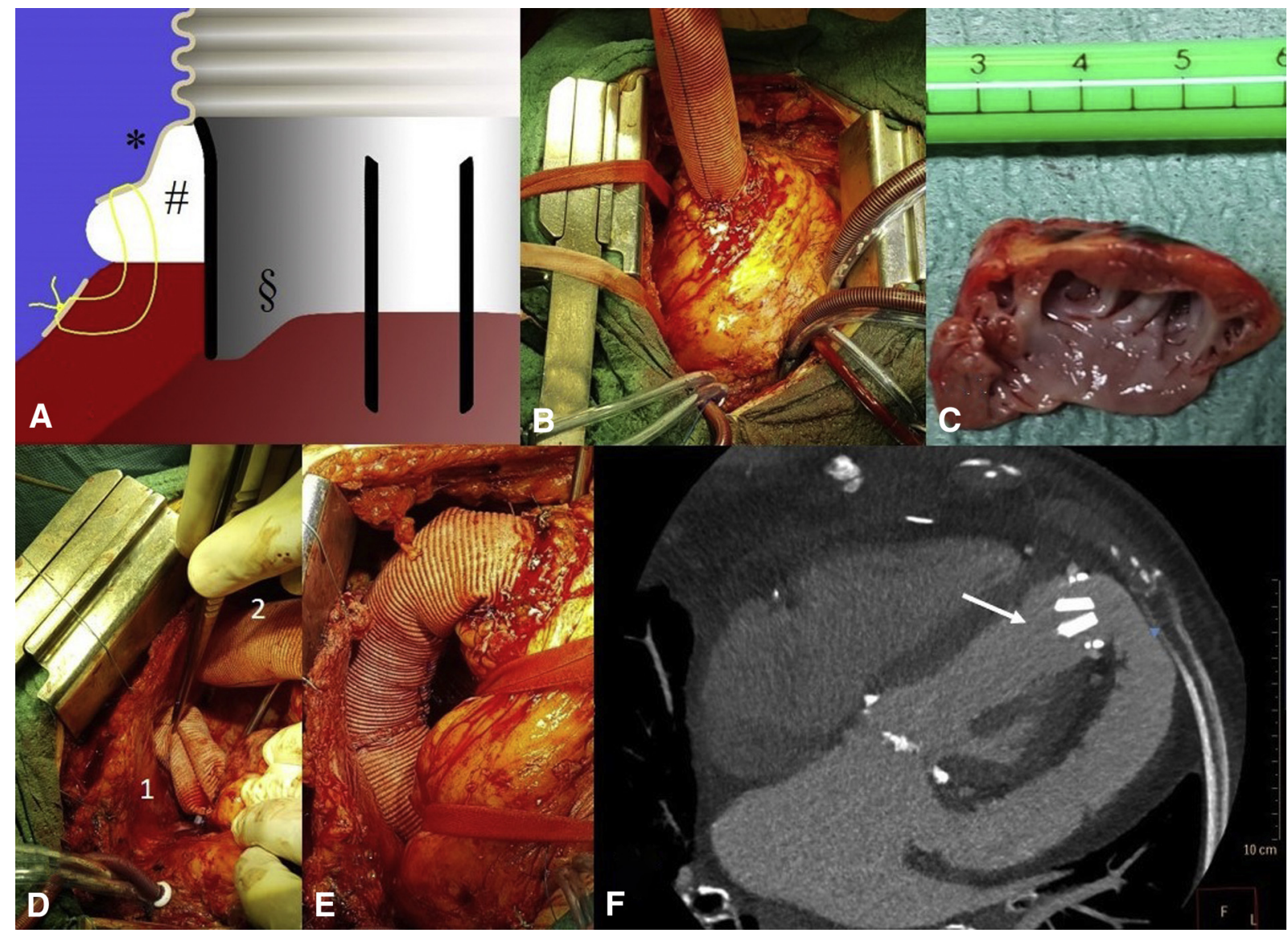

FIGURE 2. A, Pledgeted sutures around the ventriculotomy were passed through the valve sewing ring (\#) and the graft (*) at the same time, and tied down. The cylindrical housing of the prosthesis (§) shelters almost the entire motion of the leaflets. B, Mitral valve conduit sewn to the apex of the left ventricle. C, The left atrial appendage was amputated. D, The 2 portions of the graft, 1 sewn to the remainder left appendage (1) and the other to the left ventriculotomy (2). E, Completed extracardiac conduit along left side of the heart. F, Postoperative computed tomography scan showing the extracardiac left atrial to left ventricle conduit, and the mitral prosthetic valve placed in the apex (white arrow).

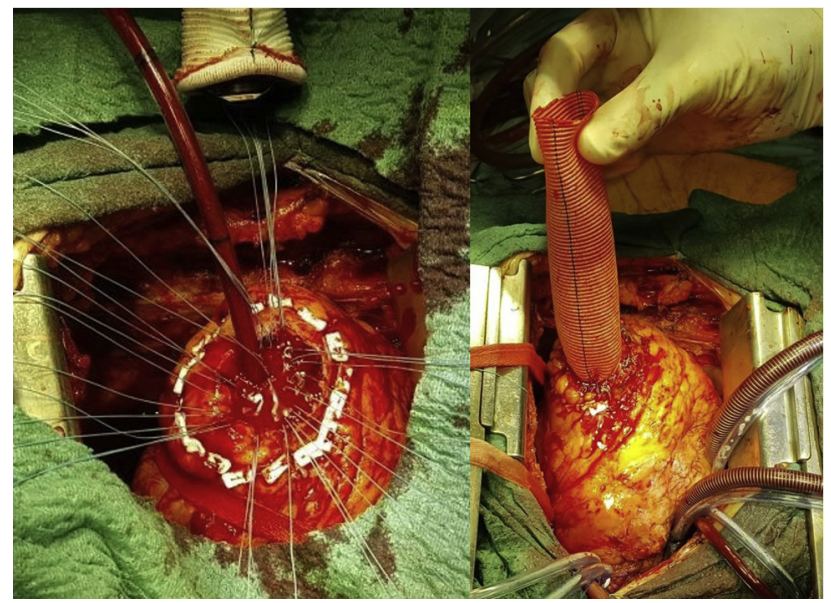

VIDEO 1. Left atrial to left ventricular bypass for mitral stenosis with severely calcified annulus and ascending aorta. Video available at: https://www.jtcvs.org/article/S0022-5223(18)32597-2/fulltext. replacement in patients with severe mitral stenosis when a heavily calcified annulus makes conventional surgery impossible. It can be performed through thoracotomy and without aortic crossclamp. However, it is contraindicated for patients with significant mitral regurgitation. Despite initial encouraging results, more cases and long-term results are required to demonstrate the effectiveness of this technique.

\section{References}

1. Uchimuro T, Fukui T, Shimizu A, Takanashi S. Mitral valve surgery in patients with severe mitral annular calcification. Ann Thorac Surg. 2016;101:889-95.

2. Smedira NG. Mitral valve replacement with a calcified annulus. Oper Tech Thorac Cardiovasc Surg. 2003;8:2-13.

3. Lansing AM, Elbl F, Solinger RE, Rees AH. Left atrial-left ventricular bypass for congenital mitral stenosis. Ann Thorac Surg. 1983;35:667-9.

4. Said S, Schaff H, Minn R. An alternative approach to valve replacement in patient with mitral stenosis and severely calcified annulus. J Thorac Cardiovasc Surg. 2014;147:e76-8.

5. Wright JS, Thomson DS, Warner G. Mitral valve bypass by valved conduit. Ann Thorac Surg. 1981;32:294-6. 